\title{
Experimental Evolution and Population Genetics of RNA Viruses
}

\author{
José M. Cuevas, Pilar Domingo-Calap, Marianoel Pereira-Gómez and Rafael Sanjuán*
}

Instituto Cavanilles de Biodiversidad y Biología Evolutiva and Departamento de Genética, Universitat de València, Spain

\begin{abstract}
Viral studies have contributed substantially to the field of experimental evolution during the last two decades. The rapid evolution of RNA viruses makes them especially suitable for investigating real-time evolution, while their small genomes facilitate the analysis of the genetic basis of evolutionary change. We review recent advances in RNA virus experimental evolution, focusing on genetic properties that differentiate them from DNA-based organisms, such as their high mutation rates, small genome sizes, low genetic robustness, and the predominance of antagonistic epistasis. We argue that these properties can explain many aspects of RNA virus evolution, including rapid evolution, marked fitness tradeoffs, frequent sequence convergences, strong deleterious effects of genetic drift, or high sensitivity to mutation accumulation.
\end{abstract}

\section{INTRODUCTION}

RNA viruses are the causative agents of important diseases affecting humans, cattle, and crops. Efforts to develop treatments and epidemiological control strategies are often frustrated by the ability of these pathogens to evolve resistance, clearly showing the need to study RNA viruses from an evolutionary standpoint. Additionally, owing to their fast evolution and small genomes, RNA viruses are excellent models for experimental evolution. During the last two decades, experimental evolution studies have contributed significantly to our understanding of RNA viruses. Conversely, RNA viruses have been used as model systems to test general theoretical population models, as for example Muller's ratchet, the competitive exclusion principle, the Red Queen hypothesis, clonal interference, or the Prisoner's dilemma, which ought to be valid for RNA viruses as well as other systems. However, in order to understand the remarkable evolutionary success of RNA viruses, it becomes necessary to pay special attention to the features that differentiate them from the rest of evolving entities. We will do so focusing on the most recent advances. Classical work in the field has been reviewed previously [1-4].

There are at least four general genetic properties that are central to RNA virus evolution. Firstly, their per-base mutation rates $\left(10^{-6}-10^{-4}\right.$ per round of replication) are orders of magnitude higher than those of DNA-based organisms [5-7] (Table 1, Fig. 1). The lack of 3'exonuclease proofreading activity in viral RNA polymerases [8], as opposed to DNA polymerases or eukaryotic DNA-dependent RNA polymerases, provides a biochemical basis for error-prone replication. Secondly, RNA viruses have small genomes, generally not exceeding $15 \mathrm{~kb}$ in length, although some closteroviruses and coronaviruses can range in size up to approximately 30

*Address correspondence to this author at the Universitat de València Apdo. 2208546071 València/ Instituto Cavanilles de Biodiversidad y Biología Evolutiva and Departamento de Genética, Universitat de València, Spain; Tel: 0034963643 629; Fax: 0034963543 670;

E-mail: rafael.sanjuan@uv.es $\mathrm{kb}$. Thirdly, recent work has established that RNA viruses show extremely low tolerance to mutation [9, 10], implying that most spontaneous mutations are rapidly purged by selection [3, 11-13]. Fourthly, the fitness effect of deleterious mutations tends to diminish as mutations accumulate [1416], i.e. epistasis is antagonistic on average. These general properties can explain RNA virus rapid evolution, but also the limits to viral adaptability. In addition, they are important for understanding the response of RNA viruses to genetic drift and mutation accumulation, as well as the nature of virus-virus and host-virus interactions.

\section{ADAPTATION}

\section{High Mutation Rates and Rapid Evolution of RNA Viruses}

RNA viruses show rapid adaptation both in laboratory [17-19] and natural environments [6]. The enormous diversity generated by the high error rates of viral polymerases is generally believed to be at the root of such adaptive potential. Clearly, high mutation rates provide increased variation for responding to strong selective pressures, hence accounting for the rapid emergence of drug-resistant viruses, for instance. Evidence for the advantage of high mutation rates under immune pressure was provided by recent studies with poliovirus, in which a high-fidelity variant showed reduced pathogenicity in mice $[20,21]$. Although current evidence indicates that RNA viruses respond rapidly to strong selective pressures, their evolutionary potential in the long-term or under weak selective pressure, and their ability to evolve new functions or capabilities, might be less spectacular [11].

A related but different question is why high mutation rates evolved. The fact that high mutation rates can provide an evolutionary advantage does not imply that they evolved because of the evolutionary advantage they bestow [22, 23]. Given that most mutations with phenotypic effect are deleterious, high mutations rates increase the mutational load in the short-term. Thus, the payoffs of elevated mutation rates are only felt in the long-term. Natural selection fails to favor traits for their future beneficial effects [23] and, given this 
Table 1. Mutation Rates for Different Biological Entities

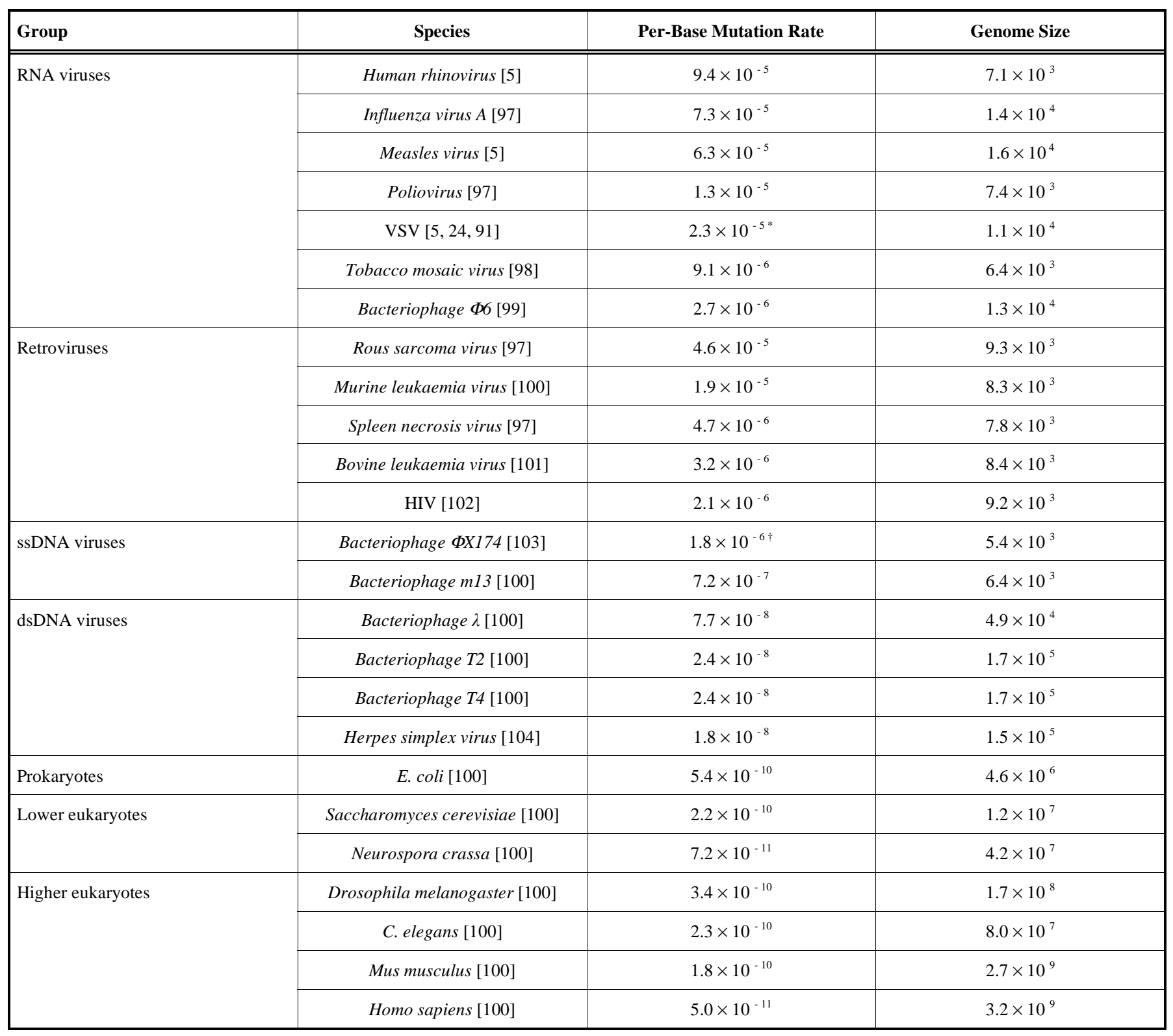

"There are five values available in total. The geometric mean is shown.

${ }^{\dagger}$ The authors reported a mutation rate of $7.4 \times 10^{-6}$ based on the spontaneous acquisition of a selectable phenotype. Sequencing of mutants showed that mutations could occur at 12 different nucleotide sites. Hence, the per-base mutation rate would be $7.4 \times 10^{-6} \times 3 / 12=1.8 \times 10^{-6}$.

conceptual difficulty, it seems natural to suggest alternative, selective pressures that would act in the short-term and drive the evolution of stably high mutation rates. In this vein, it has been postulated that the existence of a tradeoff between replication speed and accuracy could impose a direct cost to replication fidelity $[24,25]$. Alternatively, error-prone replication might simply be an unavoidable consequence of RNA biochemistry, but it has been shown that there is some room for increasing RNA replication fidelity [20, 21, 25].

\section{Fixation of Beneficial Mutations}

The nature of adaptive mutations in RNA viruses is diverse and includes synonymous substitutions [26-28]. According to Fisher's geometric model, most mutations fixed during adaptive evolution are expected to be of small effect because they should be more common than those of large effect. This classical prediction gained support from experiments with bacteriophage $\Phi 6$ in which, after a series of population bottlenecks, fitness was allowed to recover at large population sizes [29]. It was shown that fitness recovery took place in smaller steps than the original fitness decline and that there was a positive correlation between the adaptive step size and the original bottleneck size. Additionally, most advantageous mutations were compensatory. These mutations can partially or totally restore function by interacting with the primarily deleterious mutation (for example, restoring amino acid interactions that are important for the stability of the protein). Since their fitness effects are dependent on the genetic background, compensatory mutations constitute a clear case of epistasis (epistasis can be generally defined as the lack of independence between mutational effects). Compensatory mutations have also been 


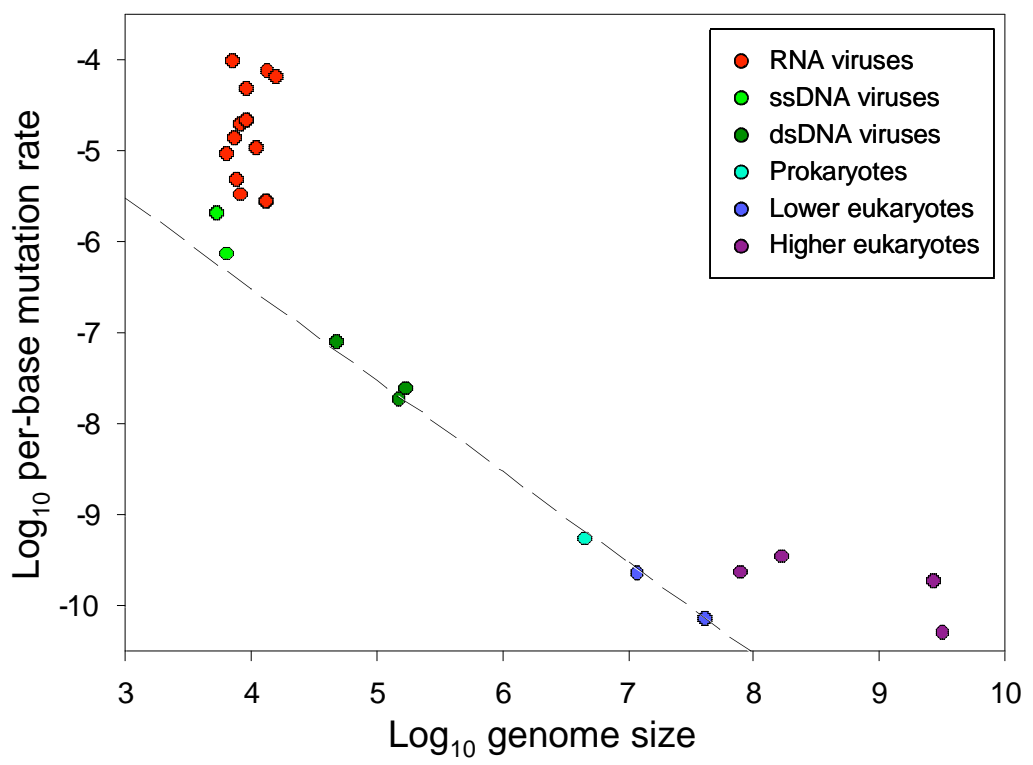

Fig. (1). Mutation rates for different biological entities as a function of genome size. Values were taken from Table 1. The dotted line corresponds to Drake's rule, which states that DNA-based microorganisms show a constant genomic mutation rate approximately equal to 0.003 [105].

shown to be frequent in Vesicular stomatitis virus (VSV) populations undergoing fitness recovery, although genetic reversions were also observed [30].

Fitness of RNA viruses and other microorganisms undergoing adaptation to a novel environment typically follows a hyperbolic-like trajectory [2]. This is in accordance with Fisher's geometric model, which predicts that the effect of beneficial mutations should decrease as the population approaches optimality, a prediction that can be also derived from clonal interference models [31]. Using site-directed mutagenesis, it has been possible to estimate the fitness effects associated with spontaneous beneficial mutations in VSV [10]. It was shown that the effects of beneficial mutations are not independent [16], but rather tend to diminish when combined (antagonistic epistasis), suggesting that the hyperbolic-like trajectory observed for fitness is not only due to the fact that the population is approaching optimality in a given environment (genotype-environment interactions), but also to the nature of epistasis (genotype-genotype interactions).

Genome sequencing of different viral lineages or species adapted to a common environment has revealed a striking amount of parallel or convergent evolution in animal RNA viruses [26, 28], plant RNA viruses [32, 33], and DNA viruses [34-38]. These parallel or convergent substitutions consist of amino acid replacements as well as synonymous changes and deletions. Another striking result is that the number of mutations fixed during adaptation of RNA viruses is surprisingly small given their high mutation rates [26, 27, 39]. Hence, adaptation of RNA viruses seems to be a rapid, simple, and repetitive process, implying that it should be at least partially predictable.

\section{Migration and Virus-Virus Interactions}

Migration is another source of genetic diversity in RNA viruses. Experimental mimicking of migratory flows indicates a positive correlation between migration rate and mean fitness in VSV, presumably because migration facilitates the spread of beneficial mutations throughout demes [40]. In the absence of migration, adaptation to new cell types becomes host-specific in VSV, thereby restricting RNA virus diversity [41]. In contrast, replication of Foot-and-mouth disease virus (FMDV) in a constant cellular environment promoted the expansion of cellular tropism [42], implying that migration would not be essential for the maintenance of a repertory of genotypes with different host-specificities. Related to this, it has been shown that viral populations in which antibodyresistance specific mutants are favored also harbor mutants with other antigenic specificities [43].

Migration in combination with high levels of co-infection increases the probability of interactions between different viral genotypes. For example, co-infection facilitates the propagation of defective genomes by complementation [44]. It has also been shown using Vaccinia virus and VSV that co-infection with a DNA and an RNA virus promotes increased adaptability of the latter [45]. Co-infection is also a prerequisite for recombination between different variants. According to the Fisher-Muller model, sexual reproduction in large populations would lead to higher rates of adaptation than in equally large asexual populations. This prediction was tested using bacteriophage $\Phi 6$ [46]. Interestingly, in this case, segment re-assortment involved a cost due to high intra-host competition. Finally, co-infection and genetic complementation can promote frequency-dependent selection, as shown for bacteriophage $\Phi 6$ [47]. Studies with VSV [48] and Human immunodeficiency virus (HIV) [49] found frequency-dependent selection under weak co-infection levels, but it must be noted that in these studies, co-infection levels fluctuated and were high at the end of each infection passage, potentially favoring frequency-dependent selection during this phase [50].

\section{RESTRICTIONS TO VIRAL ADAPTATION}

A widely accepted evolutionary restriction is one operating on RNA virus genome size [51-54]. Deterministic mod- 
els for the evolution of simple replicons at high mutation rates predict that the maximum genome size that can be maintained without loss of genetic information is inversely correlated with mutation rate $[55,56]$. Therefore, error-prone replication imposes an upper-limit to the genome size of RNA viruses. In fact, few RNA viruses have genomes larger than $15 \mathrm{~kb}$, with the remarkable exception of coronaviruses. Recent findings indicate that members of this group possess replicases with 3'exonuclease proofreading activity [57], presumably reducing the overall mutation rate and relaxing the restriction on genome size.

One might expect that, owing to their small genomes sizes, RNA viruses should display higher growth rates than more complex viruses. However, experimental data suggest the contrary. Bull et al. [58] allowed RNA and DNA phages with ample differences in genomes sizes to evolve under conditions favoring rapid growth and found that DNA phages with relatively large genomes showed the highest growth rates. Therefore, the ability to grow fast depends on genomic properties other than just size, as for instance, genetic structure [59]. In general, small genomes contain highly compressed genetic information with little non-coding and regulatory regions, frequently overlapping reading frames, and multifunctional proteins. As a result, strong functional constraints should operate in small genomes $[11,12,53]$, potentially imposing an upper-limit to the degree of evolutionary optimization that can be achieved.

Functional constraints imply that spontaneous mutations are more likely to have strongly deleterious fitness effects in RNA viruses than in more complex genomes. Indirect evidence for reduced tolerance to mutation came from early plaque-to-plaque mutation accumulation experiments [60-
63], but the drastic fitness losses observed in these experiments were mainly attributed to high mutation rates. The first unambiguous estimation of mutational robustness in RNA viruses came from a collection of VSV random singlepoint mutants obtained by site-directed mutagenesis [10]. Most mutations were found to be highly deleterious and up to $40 \%$ were lethal. These results were confirmed by a second study using Tobacco etch virus [9] and strengthen the notion that RNA viruses show very little tolerance to mutation (Fig. 2).

In another site-directed mutagenesis study using VSV, pairs of random point mutants were assayed for fitness and compared with the corresponding single mutants [16]. This revealed that the deleterious fitness effects of random mutations tended to be larger alone than in combination or equivalently, that epistasis was antagonistic on average. These results are consistent with other studies using HIV [14] and bacteriophage $\Phi 6$ [15], suggesting that antagonistic epistasis is a characteristic feature of RNA viruses, as opposed to more complex genomes [12, 54] (Table 2). Indeed, theoretical and experimental work indicates that, in general, epistasis and robustness are correlated traits, such that low levels of robustness are associated with antagonistic epistasis, whereas high levels of robustness are associated with synergistic epistasis [12, 54, 64-69]. A general explanation for the predominance of antagonistic epistasis is the socalled multiple-hit effect, whereby a given functional unit is damaged by more than one mutation, implying that successive mutations have decreasing damaging potential [12, 67, 69]. The implications of epistasis for evolution have been amply studied and include the maintenance of population genetic diversity, recombination, ploidy, or speciation, among others [70].

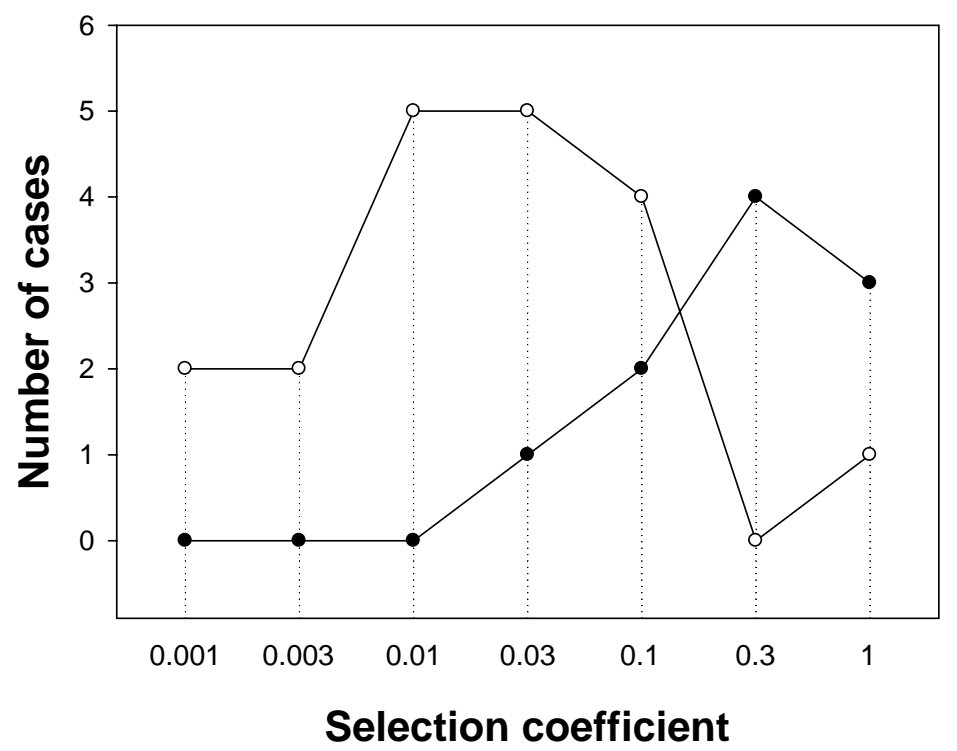

Fig. (2). Selection coefficients for RNA viruses and DNA-based organisms. Data were taken from Supplementary Tables 1 and $\mathbf{2}$ from Elena et al. [12] and updated with data from Carrasco et al. [9]. The x-axis is divided into 6 categories and the y-axis shows the number of estimates falling in each category. Black and white dots correspond to RNA viruses and DNA-based organisms, respectively. The species included are Poliovirus, FMDV, HIV, Tobacco etch virus, Dengue virus, VSV, Tick-borne encephalitis virus, Venezuelan equine encephalitis virus, Bacteriophage $\Phi 6$, E. coli, Aspergillus nidulans, S. cerevisiae, Daphnia pulex, C. elegans, Arabidopsis thaliana, and D. melanogaster. 
Table 2. Epistasis Coefficients for RNA Viruses and DNA-Based Organisms

\begin{tabular}{|l|c|c|c|}
\hline \multirow{2}{*}{ Group } & Species & Epistasis Coefficient $^{*}$ & $\boldsymbol{P}^{\dagger}$ \\
\hline \hline \multirow{5}{*}{ RNA viruses } & VSV [54] & $0.109 \pm 0.041$ & 0.001 \\
\cline { 2 - 4 } & FMDV [15] & -0.017 & $\mathrm{n} / \mathrm{a}$ \\
\cline { 2 - 4 } & Poliovirus [15] & 0.008 & $\mathrm{n} / \mathrm{a}$ \\
\cline { 2 - 4 } & Bacteriophage $\Phi 6[15]$ & 0.007 & $\mathrm{n} / \mathrm{a}$ \\
\cline { 2 - 4 } & ENA coli [54] & $0.034 \pm 0.040$ & 0.163 \\
\cline { 2 - 4 } & S. cerevisiae [54] & $-0.001 \pm 0.001$ & 0.633 \\
\cline { 2 - 4 } & Aspergillus niger ${ }^{\S}[54]$ & $-0.009 \pm 0.005$ & 0.046 \\
\cline { 2 - 4 } & D. melanogaster [54] & $-0.166 \pm 0.066$ & 0.004 \\
\hline
\end{tabular}

${ }^{*}$ Calculated as the observed fitness minus the fitness expected in the absence of epistasis [54].

Probability that the epistasis coefficient does not differ from zero [54].

${ }^{*}$ In this work, experimental mutation accumulation data were fit to a model of the form $\log W=a k+b k^{2}$, where $W$ is fitness, $k$ is the number of mutations, and $a$ and $b$ were pa-

rameters inferred from the data. The epistasis coefficient reported here was obtained as $e^{2 a+4 b}-e^{2 a+2 b}$

${ }^{\S}$ Excluding putative synthetic lethals. The estimate including these cases would be $-0.063 \pm 0.029(P=0.010)$.

As a consequence of low mutational robustness and functional constraint, antagonistic pleiotropy is believed to be especially frequent among RNA viruses. Antagonistic pleiotropy has often been studied from the perspective of host radiation. For instance, adaptation of VSV to new cell types was detrimental to their fitness in the original host [71]. In this study, for each cell type, the number and nature of the fixed nucleotide substitutions differed strikingly between the replicated evolved populations, in contrast with the homogeneity observed in their fitness values [28]. In addition, recent studies with bacteriophage $\Phi 6$ have shown that mutations conferring adaptation to a novel host tend to be characterized by negative pleiotropic effects on previous hosts [72-74]. However, RNA viruses can also evolve increased fitness in several cell types simultaneously, for instance, upon alternating-host evolution [42, 71]. In the case of arboviruses, these simultaneous fitness gains were achieved by combining mutations in single genomes rather than through genetic polymorphisms [75].

Finally, another important consequence of functional constraint is parallel or convergent evolution. As mentioned above, molecular convergences are very common among RNA and ssDNA viruses [26-28, 32-37]. As suggested by these data, viruses with small, compact, genomes can offer few different adaptive responses to a given environmental change. Also, clonal interference predicts that beneficial mutations with strong effect will become fixed preferentially in the population because those of weak effect will be often out-competed before fixation. However, this model also predicts that beneficial mutations should accumulate in an ordered way, but contrary to this expectation, $\Phi$ X174 showed parallel substitutions without a conserved order in independent viral lineages [36].

\section{GENETIC DRIFT AND MUTATION ACCUMULA- TION}

Drift is a major evolutionary mechanism in the absence of strong selection and has been extensively studied in RNA viruses [1-5, 60-63, 76-80]. The primary effect of drift is to decrease viral fitness due to the random fixation of deleteri- ous mutations. However, there are some important nuances to be made. Firstly, in nature, viruses undergo large fluctuations in population size and classical plaque-to-plaque experiments do not always capture this dynamic because population expansions in these experiments are rather modest. It has been shown that extreme transmission bottlenecks followed by large population size expansions can also lower RNA virus fitness, though this result is conditional on the mode of transmission [77]. Secondly, despite repeated bottlenecking can lead to extinction [18, 62, 63], it seems that the potential for compensatory evolution is high, as suggested by work with FMDV [81-83] and $\Phi$ X174 showing that populations subjected to repeated bottlenecks can reach a fitness plateau [84].

Whereas population bottlenecks alone often fail to trigger viral extinction, their negative effects on viral fitness are increased when combined with the administration of mutagens. The fitness of FMDV was greatly diminished in the presence of different base analogs, and populations frequently underwent extinction when these mutagens were combined with viral inhibitors [85]. Efficient attenuation was also achieved for the dsDNA phage T7 using a combination of population bottlenecks and mutagenesis [86]. Recent theory of lethal mutagenesis predicts that the mutation rate and the viral yield are the two critical parameters determining extinction [87]. Also, despite deterministic lethal mutagenesis not depending on population size, extinction should occur faster in small populations because the latter are demographically more susceptible to extinction, generate less beneficial mutations, and accumulate deleterious mutations via Muller's ratchet. Finally, there is no expected genetic signature of extinction, and experiments with Lymphocytic choriomeningitis virus failed to detect any such signature in pre-extinction populations [88]. In sum, mutagens in combination with viral inhibitors that reduce viral yield and increase population bottlenecks should maximize the probability of viral clearance. However, potential mechanisms of resistance such as the appearance of high-fidelity strains [89], mutations in the polymerase gene leading to reduced 
affinity for the mutagen [90], or increased mutational robustness [91] need to be carefully considered.

\section{CONCLUDING REMARKS}

We have shown that RNA virus high mutation rates, small genomes, low robustness, and antagonistic epistasis are deeply interlinked features. The importance of errorprone replication for RNA virus evolution is wellestablished, although the reasons why high mutation rates are commonplace in RNA viruses and not in other taxa with similar parasitic lifestyles remain to be elucidated. On one hand, high mutation rates allow viruses to rapidly respond to strong selective pressures imposed by host defenses or antivirals but, on the other hand, they increase the mutational load and impose a limit to genome size. In turn, small, compact genomes are subject to strong functional constraints, thereby limiting the long-term evolvability of RNA viruses. Extremely low tolerance to mutation, antagonistic epistasis, antagonistic pleiotropy, adaptive constraints and molecular convergences can be considered as consequences of compact genome organization.

Knowing the key factors that shape RNA virus evolution and differentiate them from more complex organisms is doubtlessly critical for efficiently combating them. An emerging research area is the study host-parasite coevolution (reviewed in [92]). For instance, antagonistic coevolution should play an important role in coexistence and genetic differentiation of natural populations as well as in the modulation of virulence in viruses and bacteria [93-96]. The study of virus-host interactions in combination with comparative biology, experimental evolution, molecular biology, and molecular epidemiology will further contribute to disentangle the key factors shaping RNA virus evolution.

\section{ACKNOWLEDGEMENTS}

This work was financially supported by grant GVPRE2008-095 from the Spanish Generalitat Valenciana to J.M.C, grant BFU2008-03978/BMC from the Spanish MICIIN to R.S., the MICINN Ramón y Cajal and Juan de la Cierva research programs, and a Ph.D. fellowship from the Spanish Generalitat Valenciana to P.D-C. We thank anonymous Referees for their comments.

\section{REFERENCES}

[1] Domingo, E.; Holland, J. J. RNA virus mutations and fitness for survival. Annu. Rev. Microbiol., 1997, 51, 151-178.

[2] Elena, S. F.; Lenski, R. E. Evolution experiments with microorganisms, the dynamics and genetic bases of adaptation. Nat. Rev. Genet., 2003, 4, 457-469.

[3] Elena, S. F.; Sanjuán, R. Virus evolution, insights from an experimental approach. Annu. Rev. Ecol. Evol. Syst., 2007, 38, 2752.

[4] Moya, A.; Elena, S. F.; Bracho, A.; Miralles, R.; Barrio, E. The evolution of RNA viruses, a population genetics view. Proc. Natl. Acad. Sci. USA, 2000, 97, 6967-6973.

[5] Drake, J. W.; Holland, J. J. Mutation rates among RNA viruses. Proc. Natl. Acad. Sci. USA, 1999, 96, 13910-13913.

[6] Duffy, S.; Shackelton, L. A.; Holmes, E. C. Rates of evolutionary change in viruses, patterns and determinants. Nat. Rev. Genet., 2008, 9, 267-276.

[7] Sniegowski, P. D.; Gerrish, P. J.; Johnson, T.; Shaver, A. The evolution of mutation rates, separating causes from consequences. Bioessays, 2000, 22, 1057-1066.

[8] Steinhauer, D. A.; Domingo, E.; Holland, J. J. Lack of evidence for proofreading mechanisms associated with an RNA virus polymerase. Gene, 1992, 122, 281-288.
[9] Carrasco, P.; de la Iglesia, F.; Elena, S. F. Distribution of fitness and virulence effects caused by single-nucleotide substitutions in Tobacco Etch virus. J. Virol., 2007, 81, 12979-12984.

[10] Sanjuán, R.; Moya, A.; Elena, S. F. The distribution of fitness effects caused by single-nucleotide substitutions in an RNA virus. Proc. Natl. Acad. Sci. USA, 2004, 101, 8396-8401.

[11] Belshaw, R.; Gardner, A.; Rambaut, A.; Pybus, O. G. Pacing a small cage, mutation and RNA viruses. Trends Ecol. Evol., 2008, 23, 188-193.

[12] Elena, S. F.; Carrasco, P.; Daròs, J. A.; Sanjuán, R. Mechanisms of genetic robustness in RNA viruses. EMBO Rep., 2006, 7, 168-173.

[13] Pybus, O. G.; Rambaut, A.; Belshaw, R.; Freckleton, R. P.; Drummond, A. J.; Holmes, E. C. Phylogenetic evidence for deleterious mutation load in RNA viruses and its contribution to viral evolution. Mol. Biol. Evol., 2007, 24, 845-852.

[14] Bonhoeffer, S.; Chappey, C.; Parkin, N. T.; Whitcomb, J. M.; Petropoulos, C. J. Evidence for positive epistasis in HIV-1. Science, 2004, 306, 1547-1550.

[15] Burch, C. L.; Chao, L. Epistasis and its relationship to canalization in the RNA virus $\Phi 6$. Genetics, 2004, 167, 559-567.

[16] Sanjuán, R.; Moya, A.; Elena, S. F. The contribution of epistasis to the architecture of fitness in an RNA virus. Proc. Natl. Acad. Sci. USA, 2004, 101, 15376-15379.

[17] Bordería, A. V.; Elena, S. F. r- and K-selection in experimental populations of vesicular stomatitis virus. Infect. Genet. Evol., 2002, 2, 137-143.

[18] Elena, S. F.; González-Candelas, F.; Novella, I. S.; Duarte, E. A.; Clarke, D. K.; Domingo, E.; Holland, J. J.; Moya, A. Evolution of fitness in experimental populations of Vesicular stomatitis virus. Genetics, 1996, 142, 673-679.

[19] Holland, J.; Spindler, K.; Horodyski, F.; Grabau, E.; Nichol, S.; VandePol, S. Rapid evolution of RNA genomes. Science, 1982, 215, 1577-1585.

[20] Pfeiffer, J. K.; Kirkegaard, K. Increased fidelity reduces poliovirus fitness and virulence under selective pressure in mice. PLoS Pathog., 2005, 1 , e11.

[21] Vignuzzi, M.; Stone, J. K.; Arnold, J. J.; Cameron, C. E.; Andino, R. Quasispecies diversity determines pathogenesis through cooperative interactions in a viral population. Nature, 2006, 439, 344-348.

[22] Elena, S. F.; Sanjuán, R. Adaptive value of high mutation rates of RNA viruses, separating causes from consequences. J. Virol., 2005, $79,11555-11558$.

[23] Clune, J.; Misevic, D.; Ofria, C.; Lenski, R. E.; Elena, S. F.; Sanjuán, R. Natural selection fails to optimize mutation rates for long-term adaptation on rugged fitness landscapes. PLoS Comput. Biol., 2008, 4, e1000187.

[24] Furió, V.; Moya, A.; Sanjuán, R. The cost of replication fidelity in an RNA virus. Proc. Natl. Acad. Sci. USA, 2005, 102, 1023310237.

[25] Furió, V.; Moya, A.; Sanjuán, R. The cost of replication fidelity in Human immunodeficiency virus type 1. Proc. Biol. Sci., 2007, 274, 225-230.

[26] Cuevas, J. M.; Elena, S. F.; Moya, A. Molecular basis of adaptive convergence in experimental populations of RNA viruses. Genetics, 2002, 162, 533-542.

[27] Novella, I. S.; Zárate, S.; Metzgar, D.; Ebendick-Corp Positive selection of synonymous mutations in Vesicular stomatitis virus. $J$. Mol. Biol., 2004, 342, 1415-1421.

[28] Remold, S. K.; Rambaut, A.; Turner, P. E. Evolutionary genomics of host adaptation in Vesicular stomatitis virus. Mol. Biol. Evol., 2008, 25, 1138-1147.

[29] Burch, C. L.; Chao, L. Evolution by small steps and rugged landscapes in the RNA virus Ф6. Genetics, 1999, 151, 921-927.

[30] Sanjuán, R.; Cuevas, J. M.; Moya, A.; Elena, S. F. Epistasis and the adaptability of an RNA virus. Genetics, 2005, 170, 1001-1008.

[31] Gerrish, P. J.; Lenski, R. E. The fate of competing beneficial mutations in an asexual population. Genetica, 1998, 102-103, 127144.

[32] Agudelo-Romero, P.; de la Iglesia, F.; Elena, S. F. The pleiotropic cost of host-specialization in Tobacco etch potyvirus. Infect. Genet. Evol., 2008, 8, 806-814.

[33] Rico, P.; Ivars, P.; Elena, S. F.; Hernández, C. Insights into the selective pressures restricting Pelargonium flower break virus genome variability, evidence for host adaptation. J. Virol., 2006, 80, 8124-8132. 
[34] Bull, J. J.; Badgett, M. R.; Wichman, H. A.; Huelsenbeck, J. P.; Hillis, D. M.; Gulati, A.; Ho, C.; Molineux, I. J. Exceptional convergent evolution in a virus. Genetics, 1997, 147, 1497-1507.

[35] Crill, W. D.; Wichman, H. A.; Bull, J. J. Evolutionary reversals during viral adaptation to alternating hosts. Genetics, 2000, 154, 27-37.

[36] Wichman, H. A.; Badgett, M. R.; Scott, L. A.; Boulianne, C. M.; Bull, J. J. Different trajectories of parallel evolution during viral adaptation. Science, 1999, 285, 422-424.

[37] Wichman, H. A.; Scott, L. A.; Yarber, C. D.; Bull, J. J. Experimental evolution recapitulates natural evolution. Philos. Trans R. Soc. Lond B Biol. Sci., 2000, 355, 1677-1684.

[38] Cunningham, C. W.; Jeng, K.; Husti, J.; Badgett, M.; Molineux, I. J.; Hillis, D. M.; Bull, J. J. Parallel molecular evolution of deletions and nonsense mutations in bacteriophage T7. Mol. Biol. Evol., 1997, 14, 113-116.

[39] Agudelo-Romero, P.; Carbonell, P.; Pérez-Amador, M. A.; Elena, S. F. Virus adaptation by manipulation of host's gene expression. PLOS ONE, 2008, 3, e2397.

[40] Miralles, R.; Moya, A.; Elena, S. F. Effect of population patchiness and migration rates on the adaptation and divergence of Vesicular stomatitis virus quasispecies populations. J. Gen. Virol., 1999, 80, 2051-2059.

[41] Cuevas, J. M.; Moya, A.; Elena, S. F. Evolution of RNA virus in spatially structured heterogeneous environments. J. Evol. Biol., 2003, 16, 456-466.

[42] Ruíz-Jarabo, C. M.; Pariente, N.; Baranowski, E.; Dávila, M.; Gómez-Mariano, G.; Domingo, E. Expansion of host-cell tropism of foot-and-mouth disease virus despite replication in a constant environment. J. Gen. Virol., 2004, 85, 2289-2297.

[43] Martín, V.; Domingo, E. Influence of the mutant spectrum in viral evolution, focused selection of antigenic variants in a reconstructed viral quasispecies. Mol. Biol. Evol., 2008, 25, 1544-1554.

[44] García-Arriaza, J.; Manrubia, S. C.; Toja, M.; Domingo, E.; Escarmís, C. Evolutionary transition toward defective RNAs that are infectious by complementation. J. Virol., 2004, 78, 1167811685.

[45] Carrillo, F. Y.; Sanjuán, R.; Moya, A.; Cuevas, J. M. Enhanced adaptation of vesicular stomatitis virus in cells infected with Vaccinia virus. Infect. Genet. Evol., 2008, 8, 614-620.

[46] Turner, P. E.; Chao, L. Sex and the evolution of intrahost competition in RNA virus $\Phi 6$. Genetics, 1998, 150, 523-532.

[47] Turner, P. E.; Chao, L. Escape from Prisoner's Dilemma in RNA phage Ф6. Am. Nat., 2003, 161, 497-505.

[48] Elena, S. F.; Miralles, R.; Moya, A. Frequency-dependent selection in a mammalian RNA virus. Evolution, 1997, 51, 984-987.

[49] Yuste, E.; Moya, A.; López-Galíndez, C. Frequency-dependent selection in human immunodeficiency virus type 1. J. Gen. Virol., 2002, 83, 103-106.

[50] Wilke, C. O.; Reissig, D. D.; Novella, I. S. Replication at periodically changing multiplicity of infection promotes stable coexistence of competing viral populations. Evolution, 2004, 58, 900-905.

[51] Biebricher, C. K.; Eigen, M. The error threshold. Virus Res., 2005, 107, 117-127.

[52] Domingo, E.; Ed. Quasispecies, concept and implications for virology, Springer; 2006.

[53] Holmes, E. C. Error thresholds and the constraints to RNA virus evolution. Trends Microbiol., 2003, 11, 543-546.

[54] Sanjuán, R.; Elena, S. F. Epistasis correlates to genomic complexity. Proc. Natl. Acad. Sci. USA, 2006, 103, 14402-14405.

[55] Eigen, M. Selforganization of matter and the evolution of biological macromolecules. Naturwissenschaften, 1971, 58, 465523.

[56] Eigen, M.; McCaskill, J.; Schuster, P. Molecular quasi-species. $J$. Phys. Chem., 1998, 92, 6881-6891.

[57] Minskaia, E.; Hertzig, T.; Gorbalenya, A. E.; Campanacci, V.; Cambillau, C.; Canard, B.; Ziebuhr, J. Discovery of an RNA virus $3^{\prime} \rightarrow 5^{\prime}$ exoribonuclease that is critically involved in coronavirus RNA synthesis. Proc. Natl. Acad. Sci. USA, 2006, 103, 5108-5113.

[58] Bull, J. J.; Badgett, M. R.; Springman, R.; Molineux, I. J. Genome properties and the limits of adaptation in bacteriophages. Evolution, 2004, 58, 692-701.

[59] Springman, R.; Badgett, M. R.; Molineux, I. J.; Bull, J. J. Gene order constrains adaptation in bacteriophage T7. Virology, 2005, $341,141-152$.
[60] Chao, L. Fitness of RNA virus decreased by Muller's ratchet. Nature, 1990, 348, 454-455.

[61] Duarte, E.A.; Clarke, D.K.; Moya, A.; Domingo, E.; Holland, J.J. Rapid fitness losses in mammalian RNA virus clones due to Muller's ratchet. Proc. Natl. Acad. Sci. USA, 1992, 89, 6015-6019.

[62] Escarmís, C.; Dávila, M.; Charpentier, N.; Bracho, M.A.; Moya, A.; Domingo, E. Genetic lessions associated with Mulelr's ratchet in an RNA virus. J. Mol. Biol., 1996, 264, 255-267.

[63] Yuste, E.; Sánchez-Palomino, S.; Casado, C.; Domingo, E.; LópezGalíndez, C. Drastic fitness loss in human immunodeficiency virus type 1 upon serial bottleneck events. J. Virol., 1999, 73, 27452751.

[64] Azevedo, R. B.; Lohaus, R.; Srinivasan, S.; Dang, K. K.; Burch, C. L. Sexual reproduction selects for robustness and negative epistasis in artificial gene networks. Nature, 2006, 440, 87-90.

[65] Bershtein, S.; Segal, M.; Bekerman, R.; Tokuriki, N.; Tawfik, D. S. Robustness-epistasis link shapes the fitness landscape of a randomly drifting protein. Nature, 2006, 444, 929-932.

[66] Sanjuán, R.; Forment, J.; Elena, S. F. In silico predicted robustness of viroid RNA secondary structures. II. Interaction between mutation pairs. Mol. Biol. Evol., 2006, 23, 2123-2130.

[67] Sanjuán, R.; Nebot, M. R. A network model for the correlation between epistasis and genomic complexity. PLOS ONE, 2008, 3, e2663.

[68] Wagner, G. P.; Laubichler, M. D.; Bagheri-Chaichian, H. Genetic measurement of theory of epistatic effects. Genetica, 1998, 102103, 569-580.

[69] Wilke, C. O.; Adami, C. Interaction between directional epistasis and average mutational effects. Proc. Biol. Sci., 2001, 268, 14691474.

[70] Wolf, J. B.; Brodie III, E. D.; Wade, M. J. Epistasis and the evolutionary process, Oxford University Press $\mathbf{2 0 0 0 .}$

[71] Turner, P. E.; Elena, S. F. Cost of host radiation in an RNA virus. Genetics, 2000, 156, 1465-1470.

[72] Duffy, S.; Burch, C. L.; Turner, P. E. Evolution of host specificity drives reproductive isolation among RNA viruses. Evolution, 2007, 61, 2614-2622.

[73] Duffy, S.; Turner, P. E.; Burch, C. L. Pleiotropic costs of niche expansion in the RNA bacteriophage $\Phi 6$. Genetics, 2006, 172, 751757.

[74] Ferris, M. T.; Joyce, P.; Burch, C. L. High frequency of mutations that expand the host range of an RNA virus. Genetics, 2007, 176, 1013-1022.

[75] Greene, I. P.; Wang, E.; Deardorff, E. R.; Milleron, R.; Domingo, E.; Weaver, S. C. Effect of alternating passage on adaptation of Sindbis virus to vertebrate and invertebrate cells. J. Virol., 2005, 79, 14253-14260.

[76] Elena, S. F.; Dávila, M.; Novella, I. S.; Holland, J.; Domingo, E.; Moya, A. Evolutionary dynamics of fitness recovery from the debilitating effects of Muller's ratchet. Evolution, 1998, 52, 309314.

[77] Elena, S. F.; Sanjuán, R.; Bordería, A. V.; Turner, P. E. Transmission bottlenecks and the evolution of fitness in rapidly evolving RNA viruses. Infect. Genet. Evol., 2001, 1, 41-48.

[78] Li, H.; Roossinck, M. J. Genetic bottlenecks reduce population variation in an experimental RNA virus population. J. Virol., 2004, 78, 10582-10587.

[79] Novella, I. S.; Quer, J.; Domingo, E.; Holland, J. J. Exponential fitness gains of RNA virus populations are limited by bottleneck effects. J. Virol., 1999, 73, 1668-1671.

[80] Poon, A.; Chao, L. Drift increases the advantage of sex in RNA bacteriophage Ф6. Genetics, 2004, 166, 19-24.

[81] Escarmís, C.; Dávila, M.; Domingo, E. Multiple molecular pathways for fitness recovery of an RNA virus debilitated by operation of Muller's ratchet. J. Mol. Biol., 1999, 285, 495-505.

[82] Escarmís, C.; Gómez-Mariano, G.; Dávila, M.; Lázaro, E.; Domingo, E. Resistance to extinction of low fitness virus subjected to plaque-to-plaque transfers, diversification by mutation clustering. J. Mol. Biol., 2002, 315, 647-661.

[83] Lázaro, E.; Escarmís, C.; Pérez-Mercader, J.; Manrubia, S. C.; Domingo, E. Resistance of virus to extinction on bottleneck passages, study of a decaying and fluctuating pattern of fitness loss. Proc. Natl. Acad. Sci. USA, 2003, 100, 10830-10835.

[84] Silander, O. K.; Tenaillon, O.; Chao, L. Understanding the evolutionary fate of finite populations, the dynamics of mutational effects. PLoS Biol., 2007, 5, e94. 
[85] Sierra, S.; Dávila, M.; Lowenstein, P. R.; Domingo, E. Response of foot-and-mouth disease virus to increased mutagenesis, influence of viral load and fitness in loss of infectivity. J. Virol., 2000, 74, 8316-8323.

[86] Bull, J. J.; Badgett, M. R.; Rokyta, D.; Molineux, I. J. Experimental evolution yields hundreds of mutations in a functional viral genome. J. Mol. Evol., 2003, 57, 241-248.

[87] Bull, J. J.; Sanjuán, R.; Wilke, C. O. Theory of lethal mutagenesis for viruses. J. Virol., 2007, 81, 2930-2939.

[88] Grande-Pérez, A.; Sierra, S.; Castro, M. G.; Domingo, E.; Lowenstein, P. R. Molecular indetermination in the transition to error catastrophe, systematic elimination of Lymphocytic choriomeningitis virus through mutagenesis does not correlate linearly with large increases in mutant spectrum complexity. Proc. Natl. Acad. Sci. USA, 2002, 99, 12938-12943.

[89] Pfeiffer, J. K.; Kirkegaard, K. A single mutation in poliovirus RNA-dependent RNA polymerase confers resistance to mutagenic nucleotide analogs via increased fidelity. Proc. Natl. Acad. Sci. USA, 2003, 100, 7289-7294.

[90] Sierra, M.; Airaksinen, A.; González-López, C.; Agudo, R.; Arias, A.; Domingo, E. Foot-and-mouth disease virus mutant with decreased sensitivity to ribavirin, implications for error catastrophe. J. Virol., 2007, 81, 2012-2024.

[91] Sanjuán, R.; Cuevas, J. M.; Furió, V.; Holmes, E. C.; Moya, A. Selection for robustness in mutagenized RNA viruses. PLoS Genet., 2007, 3, e93.

[92] Brockhurst, M. A.; Morgan, A. D.; Fenton, A.; Buckling, A. Experimental coevolution with bacteria and phage. The Pseudomonas fluorescens- $\Phi 2$ model system. Infect. Genet. Evol., 2007, 7, 547-552.

[93] Brockhurst, M. A.; Buckling, A.; Rainey, P. B. The effect of a bacteriophage on diversification of the opportunistic bacterial pathogen, Pseudomonas aeruginosa. Proc. Biol. Sci., 2005, 272, 1385-1391.
[94] Buckling, A.; Rainey, P. B. Antagonistic coevolution between a bacterium and a bacteriophage. Proc. Biol. Sci., 2002, 269, 931936.

[95] Buckling, A.; Rainey, P. B. The role of parasites in sympatric and allopatric host diversification. Nature, 2002, 420, 496-499.

[96] Morgan, A. D.; Gandon, S.; Buckling, A. The effect of migration on local adaptation in a coevolving host-parasite system. Nature, 2005, 437, 253-256.

[97] Drake, J. W. Rates of spontaneous mutation among RNA viruses. Proc. Natl. Acad. Sci. USA, 1993, 90, 4171-4175.

[98] Malpica, J. M.; Fraile, A.; Moreno, I.; Obies, C. I.; Drake, J. W.; García-Arenal, F. The rate and character of spontaneous mutation in an RNA virus. Genetics, 2002, 162, 1505-1511.

[99] Chao, L.; Rang, C. U.; Wong, L. E. Distribution of spontaneous mutants and inferences about the replication mode of the RNA bacteriophage Ф6. J. Virol., 2002, 76, 3276-3281.

[100] Drake, J. W.; Charlesworth, B.; Charlesworth, D.; Crow, J. F. Rates of spontaneous mutation. Genetics, 1998, 148, 1667-1686.

[101] Mansky, L. M.; Temin, H. M. Lower mutation rate of Bovine leukemia virus relative to that of spleen necrosis virus. J. Virol., 1994, 68, 494-499.

[102] Mansky, L. M.; Temin, H. M. Lower in vivo mutation rate of Human immunodeficiency virus type 1 than that predicted from the fidelity of purified reverse transcriptase. J. Virol., 1995, 69, 50875094.

[103] Raney, J. L.; Delongchamp, R. R.; Valentine, C. R. Spontaneous mutant frequency and mutation spectrum for gene A of phiX174 grown in E. coli. Environ. Mol. Mutagen., 2004, 44, 119-127.

[104] Drake, J. W.; Hwang, C. B. On the mutation rate of Herpes simplex virus type 1. Genetics, 2005, 170, 969-970.

[105] Drake, J. W. A constant rate of spontaneous mutation in DNAbased microbes. Proc. Natl. Acad. Sci. USA, 1991, 88, 7160-7164.

(C) Cuevas et al.; Licensee Bentham Open

This is an open access article licensed under the terms of the Creative Commons Attribution Non-Commercial License (http://creativecommons.org/licenses/by-nc/3.0/) which permits unrestricted, non-commercial use, distribution and reproduction in any medium, provided the work is properly cited. 